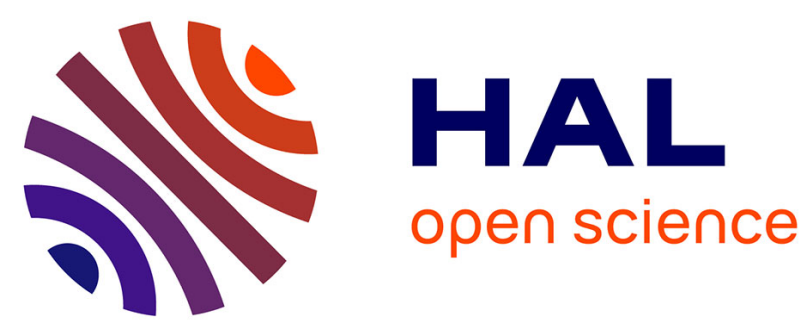

\title{
Designing for Financial Literacy: Co-design with Children in Rural Sri Lanka
}

Thilina Halloluwa, Dhaval Vyas, Hakim Usoof, Pradeepa Bandara, Margot Brereton, Priyantha Hewagamage

\section{- To cite this version:}

Thilina Halloluwa, Dhaval Vyas, Hakim Usoof, Pradeepa Bandara, Margot Brereton, et al.. Designing for Financial Literacy: Co-design with Children in Rural Sri Lanka. 16th IFIP Conference on Human-Computer Interaction (INTERACT), Sep 2017, Bombay, India. pp.313-334, 10.1007/978-3319-67744-6_21. hal-01676173

\section{HAL Id: hal-01676173 \\ https://hal.inria.fr/hal-01676173}

Submitted on 5 Jan 2018

HAL is a multi-disciplinary open access archive for the deposit and dissemination of scientific research documents, whether they are published or not. The documents may come from teaching and research institutions in France or abroad, or from public or private research centers.
L'archive ouverte pluridisciplinaire $\mathbf{H A L}$, est destinée au dépôt et à la diffusion de documents scientifiques de niveau recherche, publiés ou non, émanant des établissements d'enseignement et de recherche français ou étrangers, des laboratoires publics ou privés. 


\title{
Designing for Financial Literacy: Co-Design with Children in Rural Sri Lanka
}

\author{
Thilina Halloluwa ${ }^{1,2}$, Dhaval Vyas ${ }^{1}$, Hakim Usoof $^{2}$, Pradeepa Bandara ${ }^{3}$, Margot \\ Brereton $^{1}$, Priyantha Hewagamage ${ }^{2}$ \\ ${ }^{1}$ Queensland University of Technology (QUT), Brisbane, Australia \\ ${ }^{2}$ University of Colombo School of Computing, Colombo 07, Sri Lanka \\ ${ }^{3}$ Sri Lanka Institute of Information Technology, Malabe, Sri Lanka \\ \{tch, hau, kph\}@ucsc.cmb.ac.lk, pradeepa.b@sliit.lk \\ $\{d$. vyas, m.brereton\} @qut. edu.au
}

\begin{abstract}
Financial literacy can play an important role in supporting the livelihood of the poor. Sri Lanka, being a country that aims to become a knowledge economy, has started to integrate the use of technology in its primary education. This paper presents a case study from a Co-Design activity with primary school children in rural Sri Lanka to ideate designing of mobile applications to engage primary school students in financial literacy. Three workshops were conducted spanning over two months based on the bonded design method. Techniques involving bags of stuff, storyboarding and stickies were utilised to support idea generation. Two themes; shopping and transporting were prominent among the final designs. From the findings of this paper, we discuss the design inspirations of the study and the impact that scaffolding practices had on the outcomes of the study. Finally, we lay out some initial guidelines to follow when conducting co-design workshops with rural and resource constrained children in Sri Lanka.
\end{abstract}

Keywords. Co-Design, Financial Literacy, Children, ICT4D

\section{Introduction}

"We can end poverty" is the theme of the United Nations' 2015/2016 development plan and eradicating poverty has been listed as the main millennium development goal [55]. The World Bank reports that almost half of the world's population lives on less than USD 3 per day [62]. In the Sri Lankan context, the Ministry of Finance and Planning reports that approximately 1.3 million individuals are living in poverty with earnings of around USD 25 per month [33]. Approximately, 86.8\% of them are from rural regions where resources are poorly distributed. Furthermore, there is a significant percentage of individuals living 'just above' the poverty line. If the poverty line increased by USD 2, the people who are living in poverty will be reaching 2.0 million [33]. That is close to $10 \%$ of the countries' population. Consequently, about 1.5 mil- 
lion families are depending on Samurdhi, which is social welfare scheme by the government to the low-income families [53].

Financial education can play a vital role in a country's social and economic growth. A significant correlation exists between economic development and financial education [21]. Recent reports indicate that the average debt of a Sri Lankan family has increased from USD 355 to USD 1325 since 2009 [9]. The Central Bank of Sri Lanka has started conducting financial educational programs for low-income families as a solution. It is reported that the financial education should start at school and has to be learned as early as possible [40]. By understanding the importance of financial literacy for children, education systems around the world have started integrating it to the school curriculums as a part of the Mathematics syllabus [52]. With Sri Lanka being a country with a high literacy rate and a relatively small population, the government has a focus on a knowledge economy with a service sector instead of a manufacturing industry [16]. In 2016, the government has proposed to introduce tablet computers to Schools as a learning tool [29]. Drawing inspiration from this initiative of introducing tablet computers to secondary schools, a pedagogical approach is investigated to identify ways to utilize them to enhance the financial literacy among the young learners in Sri Lanka.

Introducing new technological devices is only one aspect of a solution. Additional investigations are required in making these devices productive and to design applications which cater the requirements of these children. Understanding the context of the users and the relationships between individuals, artefacts and practices are key considerations for the effective design of technological tools [36]. This awareness helps designers to design tools and technologies which fit the spaces the users occupy. Thus, we have conducted a series of co-design workshops to obtain design inspirations for designing mobile applications towards enhancing the financial literacy of resource constrained primary school children in rural Sri Lanka. We collaborated with a public school, where most of the students were from neighbouring orphanages. They were deprived of facilities such as the Internet and even electricity. All the participating students had very limited exposure to technology. The main contribution of this work is to showcase the co-design procedures in a post-colonial environment while the overall aim of this study was to generate design ideas to implement a mobile application for Sri Lankan schools focusing on financial literacy. This paper will feed results into a larger scale government sanctioned project on designing applications for financial literacy.

The workshops were held within one school semester spanning over two months. We were allocated one hour per session by the school administration to accommodate routine teaching and learning activities. The children participated as co-designers in all the workshops. Design inspirations for creating mobile applications to promote financial literacy were developed incorporating a variety of methods. Methods such as bags of stuff [15], storyboarding [54] and stickies [15] were used to draw out ideas from their day to day experiences in interacting with money and to evaluate the designs. The use of a variety of techniques enabled the research team to gain a comprehensive understanding of children's sentiment towards money. 
Over the past three decades, the HCI community has shown a great interest in getting children involved when designing tools and technologies for them. While many of these studies conducted in the developed world $[26,31,45,58]$, there is a lack of similar work in the developing world where the teaching and learning environment is significantly different [19]. Hence, we present a case study conducted with primary school children in rural Sri Lanka to investigate how to design with children. The purpose of the paper is two-fold: Firstly, to provide some initial inspirations on the metaphors to be used when designing for resource constrained children in the developing world. Secondly, lay a layout on a set of guidelines to be used when conducting co-design workshops in a developing country. We find that instead of directly utilizing the methods used in the developed countries, some initial time needs to be spent on getting the children familiar with the co-design approach due to cultural diversities. All the designs were inspired by the children's day to day experiences and they needed them to be expressed as realistic as possible. Before describing the workshops, we present related work in constructing a rationale for our design workshops

\section{Related Work}

\subsection{Children and Financial Affairs}

Children in the modern society do not live in isolation and they directly interact with the world economy [56]. The ability to manage finances is one of the critical skills to acquire. This skill is mostly acquired in childhood [1]. Consequently, studies conducted by Beverly and Burkhalter [6] and Cohen and Xiao [8] recommend that the financial education needs to be provided as early as possible starting from preprimary education. It will help prepare young people to make better financial decisions [30].

The United States Department of the Treasury [13], reports that the financial education should be integrated into the school curriculum as part of mathematics and reading curricula starting from elementary school, as it lays the foundation for making effective financial decisions throughout their lives. Northern Ireland has embedded activities [38] to their primary mathematics syllabus to help promote financial understanding in an attempt to alleviate the problem of financial exclusion. These recommendations are supported by research which states that children begin to understand the concept of money by the age of 3 and understand the importance of saving money between ages six and twelve [52]. By the age of 12, children start engaging in more complex saving and spending strategies [18]. Understanding the importance of financial literacy for children, education systems globally have started integrating it to school curriculums [52]. Metcalf and Atance [32] report that even though the children were not inherently motivated to save, they can be taught the importance of saving even after a single trial. Otto et al. [39] have used a game to explore the age differences in children's ability to apply saving strategies. Of the two studies, first was conducted with 42 children and the second was with 36 children (ages $6-12$ ). They 
report that between ages nine and twelve, children gain the ability to manage their money, learn to manage bank accounts and use banking functionalities.

\subsection{Co-Designing with Children}

When technology is implemented for children, it is critical to involve them in all aspects of design which allow designers to come up with tools and technologies capable of catering a child's requirements [12]. The lack of preconception about the design space makes the children aged between 7-10 the best candidates for these type of studies [43]. Previous studies discuss various ways children can be involved in the design. Druin [12] reports that the children should be involved as design partners where the adults and children are treated as equals while Read et al. [43] suggest different levels of involvement, namely informant, balanced and facilitated. However, it has been identified that there is an unequal power relationship between adults and children which presents a significant barrier especially in the school environment [3,51]. Another concern raised when involving children as design partners is that most children are not trained to provide critical feedback [43].

Over the years, many methods have been introduced for designing with children. Cooperative inquiry [12] is a philosophy where children are considered design partners and work together with adults as equals. Informant design [46] by contrast advocates input from different people at different stages in order to effectively maximise the value of their contribution to the overall effort Bonded design [27] sits in between cooperative inquiry and informant design by uniting a team of intergenerational people, drawing upon and recognising their different insights and strengths. In the bonded design method, the design partners work with researchers for shorter periods of time. Furthermore, the bonded design method allows the design partners to be considered as learners in addition to being designers. This method is ideal when the designers are unable to work with children for a longer period of time. Kidstory [51] is another method which is an adaptation of cooperative inquiry that enables a large number of children to participate in the design. The Child Computer Interaction (ChiCI) group use a method named The Mad Evaluation Session with Schoolchildren (MESS) [44] which has more emphasis on evaluation and fun. PICTIVE [35] is an approach that uses papers and pencils to get non-computer-literate users involvement. Designing organic user interfaces by means of PlayDoh, small Lego bricks, fabric shapes etc. have also been investigated [42]. Doorn et. al. [11] have explored a method where they get children involve as researchers to gain rich contextual insights. IDEAS [5] is a method for involving autistic children in designing. Furthermore, there are various techniques been introduced such as bags of stuff [65], storyboarding [54], layered elaboration [59], etc. [60] to get children engaged in these studies.

Utilizing the above-mentioned methods and techniques; many studies have been conducted by various researchers in varying contexts over the last two decades within the HCI community. Alborzi et al. [3] have investigated on getting children into designing immersive storytelling environments. Frauenberger et al. [17] report that it is essential to focus on ways to interpret the inputs and ideas of Children. Engaging children on designing tools to address issues related to mental health is another ave- 
nue which has been explored [37]. Kwon et al. [26] have engaged children in designing a social mobile learning application. Another study focusing on improving the Namibian reading culture [23] outlines how they utilized participatory design in different levels to gather design inspirations. Makhaeva et al. [31] report how they created creative spaces for co-designing with autistic children using a concept named "Handlungsspielraum". One similarity in all these studies is that it was the adult partners who led the sessions. However, it has been identified that the children can also initiate and lead these type of co-design workshops [64] as long as they are sufficiently trained.

\section{Designing with children from the developing countries.}

Researchers often assume the availability of stable and reliable power supplies, affordable and ubiquitous cell coverage and internet facilities when designing for the developing countries [2]. However, in many of the developing countries, none of these assumptions are guaranteed. Irani et al.[22] referred to this differences and the challenges faced in the developing world when designing, under the umbrella of "postcolonial computing". They also propose a formulation of design work based on engagement, articulation, and translation. Suchman [49] has also reported the differences in practices and the importance of not relying on the assumptions made at the "hyper-developed world" when designing for post-colonial or marginalized populations. Culturally situated design[14,47] is another concept which states the importance of designing for a particular culture by referring to the designs which are grounded in the designers own culture. This understanding enables them to interpret the designs unambiguously. A study[48] reports that children from technology savvy environment can design for children who are technologically challenged. This was done with 50 children from a UK primary school where they designed a game related to hand washing for children in Uganda. However, it can be said that the study produced positive results because the idea of handwashing is generic enough to be played by a global audience. Another similar study[47] conducted with children from a UK primary school with the aim of investigating the use of sensitizing techniques' impact on designing for a surrogate population (rural china) reports that most of the designs put forward by the children are culturally un-situated. Even though these children were given enough time to get familiar with the Chinese culture, most of their designs did not reflect that knowledge and were culturally neutral. Nonetheless, it is clear that when designing for marginalized and culturally diverse communities, the researchers themselves should have aa grounded understanding of the targeted audience.

Kam et al, [24] have carried out a study on designing digital games in a rural Indian village with students from three schools. They have given students to play a game for 1.5 hours. These games were traditional village games. They state that it is easier for rural children to relate to technologically enhanced education systems if it has the same game mechanics as a traditional game. The focus of the study was on designing for keypad mobile phones. Another study [25] has attempted to integrate mobile phones in an Indian village has focused on exploring how unsupervised mobilelearning is done in rural India. They report how village children used mobile phones in their day to day lives along with their improvements in English as a second lan- 
guage. Even this study was done using basic mobile phones and not in a classroom environment. Larson, et al. [28] have conducted an experiment with 63 students in India on improving English literacy. This is a mobile game, based on the popular sport cricket, targeting to improve pronunciation skills of rural Indian children. Nevertheless, this was done using low end basic mobile phones. One Laptop per Child (OLPC) is a concept that was introduced to promote technology use in primary education in developing countries. This initiative has shown both positive and negative impacts in different contexts. For instance, a study was done in Ethiopia [50] which focused on child literacy have shown positive results while in the US [61] it was identified a failure due to various factors. recently, The OLPC Sri Lanka initiative reports that "only giving XO machines did not make a big change among these young learners in general" [20]. They claim that the background has to be set including conducting teacher training and setting a sound pedagogy. Ames [4] argue that the positive results and claims made by OLPC studies in the developing world are mainly due to the charismatic nature of the device.

While these studies haven't incorporated participatory design techniques or involved children as design partners, they probe deep into the varying cultures, practices of rural communities through an ethnographical approach. Hence, our paper provides a first in-situ study which looks at designing with children in a South Asian developing country.

\section{The Study}

\subsection{Method}

Three workshops were conducted based on an adaptation of the Bonded Design [27] method. This method describes several stages in design such as team building, viewing and critiquing, drawing, brainstorming, games, journaling and evaluating. All the workshops were conducted in the schools instead of a lab environment.

Since the study involved working with children, the study was done in compliance with our institute's ethical committee regulations, where parent/guardian consents were obtained in writing. Special permission was also sought from the Department of Education, Western Province, Sri Lanka. All the participants and their parents/guardians were informed that the participation in the study was voluntarily and they could opt out at any given time without having to provide reasons.

A qualitative approach was used for gathering and analysing data. All the workshops were video recorded and three researchers actively took notes throughout the study. Both teachers and students were interviewed after the study. These were semistructured interviews where we aimed to understand their learning experiences of designing with peers. Each interview was approximately 10-15 minutes and took place immediately after finishing the study. Interview data was transcribed. Thematic analysis [7] was used to analyse the transcriptions and video clips of field study observations that were made in the school setting. 


\subsection{Participants}

The participants for the workshop were 24 primary school children (Age 8-9) with very limited exposure in playing mobile games and three adult researchers. These children were selected based on the findings of Read et al., [43] as they report that children in this age groups are the ideal candidates for designing with. Druin et al, [12] report that the children can be used in these type of workshops in different forms, namely, user, tester, informant, and design partner.In our workshops, the children took part as design partners where they become an integral part of creating a technology. All the children were present throughout workshops. The adult researchers participated as facilitators and motivators. They lead the discussions and guided the children in designing by asking "what if" questions.

\section{3 "The Play Room" workshop}

When developing an engaging and sustainable learning tool for the children, it is essential to involve them from the initial ideation process [12] which makes the children co-designers. Consequently, to be effective co-designers, they need to have a proper understanding of the process of co-design, the fundamental concepts, and subject knowledge. However, as this is the first co-design workshop that is been done with Sri Lankan primary school students and due to their demographics, these children are likely to have no or little experiences with either using these type of mobile devices or the process of designing. To overcome this situation, we designed "The Play Room" workshop. Through this workshop, we attempted to simulate the first two stages of bonded design; team building, viewing and critiquing,

We believe that when introducing something new to a child, it has to be introduced gradually. "Instructional scaffolding is the provision of sufficient supports to promote learning when concepts and skills are being first introduced to students. These supports are gradually removed as students develop autonomous learning strategies, thus promoting their own cognitive, affective and psychomotor learning skills and knowledge" [57]. Researchers argue [34] that this is the formal implementation of Vygotsky's "Zone of proximal Development" which refers to the gap between what a child can achieve alone and what a child can achieve with the help from an external party. In that sense, the play room workshop was intended to be a scaffolder so that the children can gradually learn the process of co-design while getting an experience for using mobile devices.

For the first part of this intervention, the researchers went to the school and observed the teaching and learning environment. This is done for two days with the same teacher who taught mathematics. The sessions were video recorded. Afterwards, we conducted "The Play Room" workshop to understand the feasibility and limitations in participant recruitment, technical and logistic constraints, to observe how participants will respond and to determine the duration of an effective session. We designed two overhead cameras to record the work of the children in order to ensure that the video recording was nonintrusive and instantaneously oblivious to the participants. 
This workshop was utilized as an icebreaker session to build relationships with the children and researchers. Icebreaking is critical to narrow the power gap. Since most Sri Lankan students are not used to talking freely with their teachers (adults) and expressing ideas, we used this session to make friends with them, get to know them better and build trust. The students were discouraged from raising their hands and standing up when they wished to make a point as we needed them to address the researchers as freely as possible. Workshop series was conducted throughout a week (1 hour per day). The workshop started by researchers introducing themselves to the children and telling them about their school days and how subject such as mathematics influenced them in their personal lives (failures and successes). The idea behind this was to use this activity to help the children get over their fear of failure and to get them to start talking about their ideas. During this workshop series, all 24 children took part in playing mobile games, drawing activities and discussing their thoughts on the games they were playing.

\section{4 "Build a Game" workshop}

The Build a Game workshop was conducted one week after "The Play Room" workshop. It was conducted as four one-hour-long sessions within four days. This workshop simulated the drawing, brainstorming and journaling stages of bonded design. This workshop series used a variety of methods to brainstorm ideas and initiate discussion with children.

Eight teams were formed with three children per team. As there were only three adult researchers, one researcher had to be a part of two groups. Each team was asked to develop one or more prototypes (depending on the ideas they generate) to represent their experiences with interacting with money and visualize those experiences in a form of drawings. Semi-structured interviews were carried out during and after the workshops while the children describe their ideas.

As techniques for engaging children in design, a combination of Bags of stuff and Storyboarding [15] were used. Bags of stuff uses art supplies for the creating low fidelity prototypes and storyboards usually illustrate a scenario of how an application feature works. The art supplies were provided in a form of a large bag filled with items such colouring pens, glue, paper, markers, scissors, and cardboards. Using the items provided the children were asked to create stories.

\section{5 "SCORE" workshop}

This was a two-day workshop where children used the stickies [15] method. The sticky notes were used to record one idea per note of their likes, dislikes, and design ideas about another teams' designs. This workshop is similar to the evaluation stage suggested by the bonded design method. After the session, the three adult researchers organized these notes into groups in an attempt to identify themes. This helped the researchers understand the outcome of the session while using it as evaluating mechanism for the prototypes. 


\subsection{Data Collection and Analysis}

For all 3 workshops, we collected video data, field notes, photographs, design artefacts in the form of storyboards and sticky note artefacts. We also conducted brief semi-structured interviews with all child participants on their thoughts on the workshops. The data analysis was done through a cross-validation of video data, interviews, artefacts, and field notes to explore evidence related to our research questions. We also examined behaviours and attitudes the children showcase during these three workshops. As the authors involved are from different geo locations, all the data was placed into a secure online data storage in which the videos, field notes, photos, and artefacts could be analysed by each author [63]. To strengthen the validity of our findings, each author explored the evidence independently and across analysis was done to investigate the difference and/or similarities of each.

\section{$4 \quad$ Findings}

\subsection{Observations of "The Play Room" workshop series}

The education culture of most Asian countries is non-participative while the teacher is usually considered as an authoritative figure [41]. This is true for Sri Lankan education as well. The teaching is mostly done using the chalk and talk method. Teachers complain that due to a large number of students in a classroom (40 45) they cannot pay individual attention to each student.

During our observations, we realized that the teacher works relentlessly to get the students to learn what she was teaching. We also noticed that she put an extra effort to her teaching as she was aware that we were filming. She encouraged the students to keep quiet in the classroom during the teaching period by utilizing techniques such as asking them to raise hands when they start shouting. However, we could observe that some children refrain from asking questions from the teacher due to this practice. Later a child confided in us stating "I was afraid to ask the teacher then and I waited till she finished, but I forgot to ask it from her after the session". We realized that this reluctance to communicate openly could be a barrier in our co-design workshops. Hence, we decided to have an icebreaking workshop to build trust and confidence among the children.

During the initial stages of the workshops, the children were hesitant to talk freely and they tried to treat us with the similar respect they have for teachers. For an instance, when we ask a question, they would raise a hand, and if asked would stand up and answer. However, once the session progressed they seemed to be more relaxed and talked freely with us. Additionally, they seemed nervous in answering questions such as "What is your favourite subject?". When the teacher was around, all of them said they liked Mathematics best. Therefore, we asked the teacher to leave the room and afterwards, 5 children said they liked "Art" best and 2 said, "Sinhala" (mother tongue) is their favourite subject.

The second session involved playing 5 educational mobile games where shopping was the main theme. They were asked to play the games even though none of them 
have played a mobile game before (Fig.1-a). While this was done as an ice breaker, we did not hesitate to try and learn children's perspectives about the games they were playing. We used this to see which interactions are intuitive and which are not. The children were informed that they can ask for help if necessary. We were particularly mindful not to ask any "Leading" questions. Since the game was in English, none of the students could understand the instructions given and they had difficulties in understanding some of the icons used. We realized that the children were just trialing and learning. This was evident in one of the game plays which involved a bakery. The player can bake a cake and sell it. Nevertheless, the children kept on baking cakes even though they have made one cake. They confided that they thought the game was about making a cake instead of a shopping game. All the games highlighted every element that needs to be clicked in a hierarchy. The children seemed eager to click/touch on anything blinking or anything with bright colours. Hence, most of the children were able to get by playing the game, even though they didn't understand the spoken language. While we perceive this as to be an effective mechanism to make interactions intuitive to novice users we also observed that the children who took the time to learn how to play, showed signs of frustration though out the session even though they had learned.

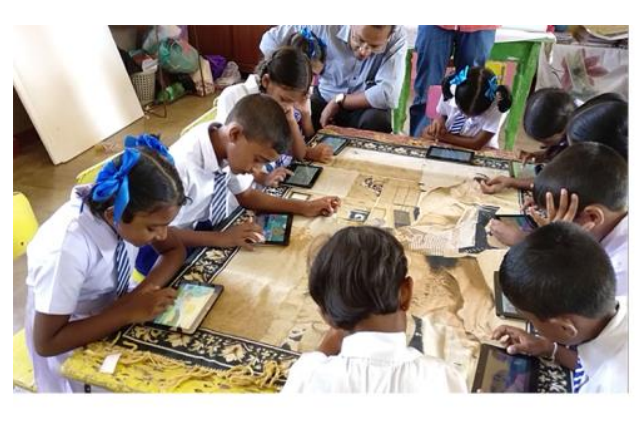

(a)

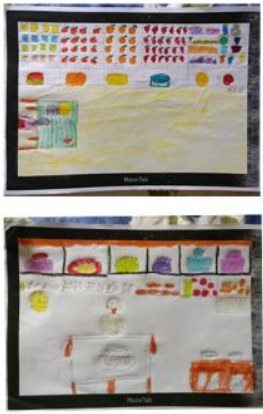

(b)

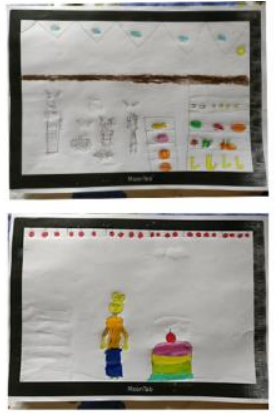

Fig. 1. (a)The children playing the mobile games for the first time and explain their thoughts, (b) some of the drawing artefacts from the children illustrating their favourite scenarios of the games

At the end of the session, we conducted a semi-structured interview session where the children discuss their ideas, likes and dislikes about the games they played. They prefer writing them down and we collected the notes as evidence. The session concluded with a drawing activity where the children would draw scenario from the games they played (Fig.1-b). As the session progress, we realize the children get used to handling the devices and playing games. Initially, they were struggling with device features such as screen timeouts and rotations. But after some time all of them got used to it and learned how to turn the screen back on. The children stated that they liked the metaphors used in the games, especially the cartoon characters. However, they explicitly mentioned that they would prefer if the games were in the Sinhala language. All these activities (the initial discussion, playing the game, discussing the 
likes and dislikes, drawing activity) were done to train the children for the upcoming workshops as these children were new to these type of interventions.

\subsection{Artefacts of the "Build a Game" workshop}

The focus of this workshop was to design game scenarios as paper prototypes. Most groups preferred to work as teams while one group of students wanted to work individually. However, we could observe many intra-group and inter-group discussions among the children.

While it was notable how the experiences and sometimes hardships of these children were expressed from their designs, we could observe very little idea diversity among the designs. Two themes of design were common among most of the groups and only one child, a member of the team that preferred to work individually came up with a design outside of the two common themes.

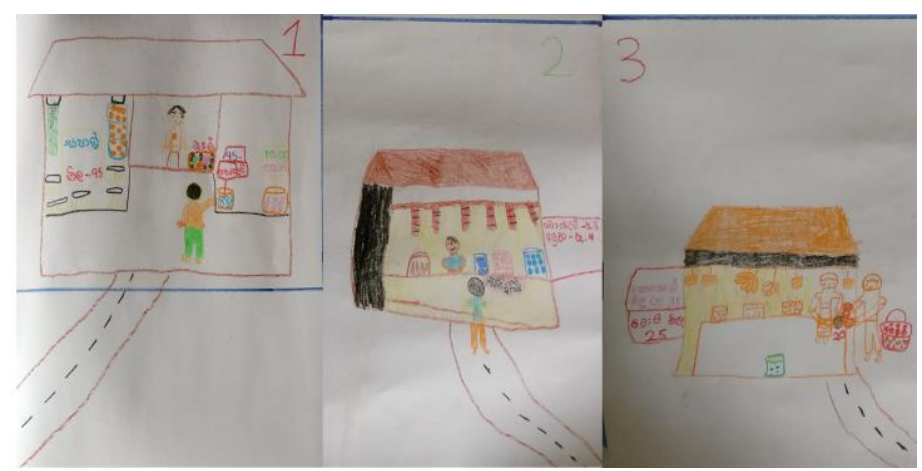

Fig. 2. A story of going to a village shop and buying items. The numbers $(1,2,3)$ are used to explain a specific event such as going to the shop and paying.

The most common theme out of the two was "Shopping". All the children drew their shops as a small village shop as opposed to larger supermarkets. The majority of the items sold were sweets and fruits while the character of shop owner resembled a typical village character or a little child. One of the children mentioned that she drew "Nihal Mama" (Uncle Nihal) who happened to be the owner of the school canteen.

In all the drawing, the character of the shopper was always a child, either walking to the shop or taking a bus to the Pola (open market). The children stated that it is how all of them go to the shop as none of them owned a bicycle but they, of course, preferred to ride a bicycle.

One group of children explained their story by roleplaying. One child assumed the role of shopkeeper while the other two children played the role of shoppers. They listed down the prices of items and they did the calculations on the drawing itself so that we (the researchers) would understand their drawings better (Fig.3). Discussions with the teachers have revealed that she utilizes the same technique in some of her teachings as the children respond favourably to learning activities when embedded in storytelling or role-playing activities. 


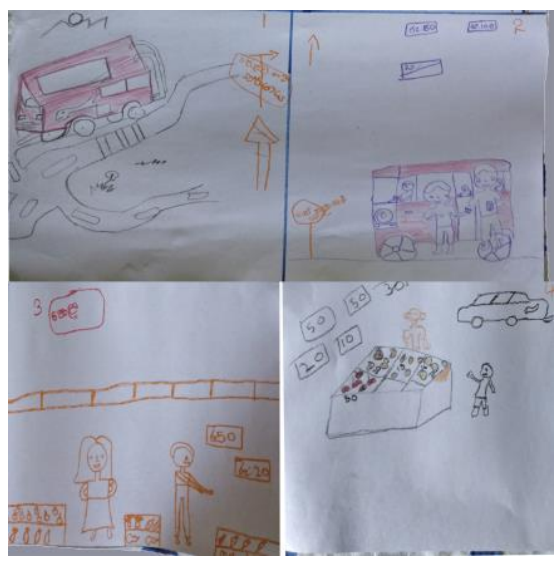

Fig. 3. The story of going to the market by bus. This was a detailed drawing illustrating going to the bus stop, waiting till a CTB bus arrive, going to the market, buying goods and return by a taxi.

The other common theme was transportation, either by bus or by train. Here the children drew scenarios where they would travel either to school or visit family. It was fascinating to see how extremely detailed some of the drawings were. For instance, one drawing illustrated the bus stops and explicitly mentioned the way to the market. An interesting observation was the colour of the bus. In all the drawings, the bus was coloured in red. The red colour busses are the Sri Lanka transport board (CLTB/CTB) bus and they offer a discounted price for school children and they implement season tickets at a subsidiary rate. The children stated that they would always wait for a CTB bus. One team has decided that they want to draw a complete story which represents the scenarios where they would interact with money. Here, the characters would take a bus to the market, buy items and return home from a taxi or a three-wheeler (tuk-tuk). There were numbering the screens, using arrows and even writing instruction as next scene as a means of the guiding the teacher to follow their story since the teacher was not there and the signs would help her construct the story.

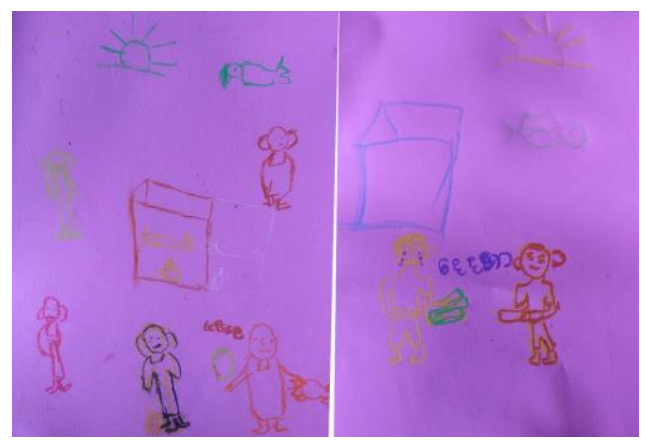

Fig. 4. The drawing of the debt payment scenario. The left-hand board shows a scenario of taking on a debt from the village butcher while the right side board shows the payment of debt. 
The only artefact, which was outside these common themes, was produced by the team where individuals preferred working alone. One of them drew a scenario where his father is obtaining a loan from the village butcher and paying a debt of Rs.2000 ( 13 USD) he owed. In his picture, the character of the father was crying while the person taking the money was smiling. He stated "Yesterday I went with my father to meet an uncle and my father gave Rs.2000 to him. I saw my father was saddened when he handed over the money".

Apart from these observations, we could see that the children who said art was their favourite subject finish their stories and help other students while some struggled to finish their work. However, in the end, all the children expressed that they enjoyed the workshop and asked about the next workshop.

\subsection{Outcomes of the "SCORE" workshop}

During the SCORE workshop, we observed that all the students facing difficulties in writing their likes, dislikes and design ideas on small sticky notes in the Sinhala language. This is understandable as the language skills nor critical thinking skill of these children are not yet fully developed. Therefore, we adapted a method introduced by the bonded design for evaluation where the children complete a simple questionnaire. The children wrote down the likes, dislikes, and ideas to improve the designs on a piece of paper provided. While the children were writing down their ideas, semistructured interviews were conducted with them to understand the meaning of their writings. For example, one child has written that he disliked the fact that the "Money is on display" and what he actually meant to say is that he didn't like the way the values of the notes/coins were written instead of drawing the actual note/coin.
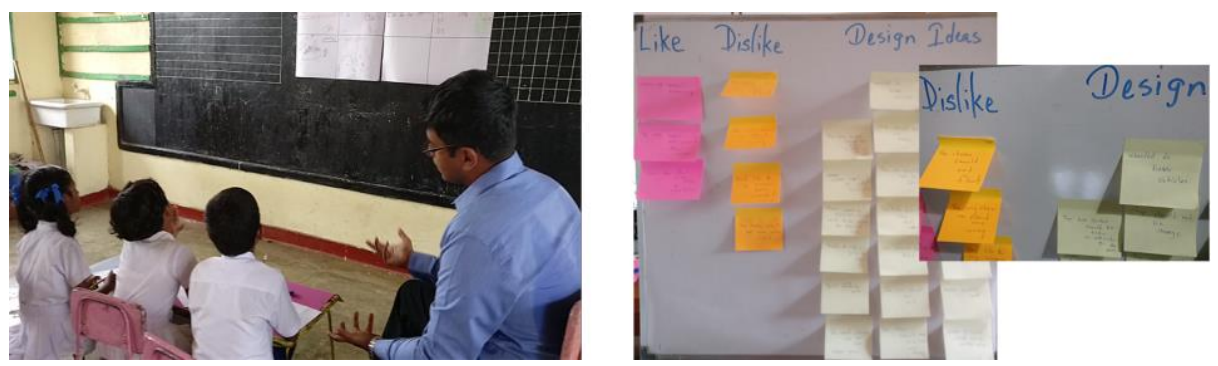

Fig. 5. The Sticky session. Each team took a turn in examining other team's work and wrote down the likes, dislikes and design ideas to improve those artefacts.

We observed that almost all the children having difficulties in distinguishing dislikes over design ideas. The also struggled with finding points which they like and we believe that is because they are not trained to provide critical but constructive feedback. Therefore, initially, the small groups gave more design ideas and did not give likes and dislikes. As a result, at the end of the workshop, we organized 3 likes, 4 dislikes and 21 design ideas for all designs. Another notable observation was that the children did not like evaluating the work of their friends when they were present in 
the room. Therefore, we had to get one team at a time to evaluate the designs of their peers. Once this task was complete, we got all the teams together and read every note to them. Initially, the teams kept quiet when there was a criticism to their designs but after some time they became defensive towards criticism. For instance, in the artefact where one team have described a scenario with a bus, the bus ticket was issued outside of the bus. One of the children challenged this by saying "This is unrealistic; all bus conductors issue tickets inside the bus". The team which designed that artefact retorted, "No the long distance buses issue tickets before getting on the bus, you just haven't traveled in one of those". We observed some children were unengaged who later revealed that they were "nervous but felt more comfortable as the session progressed".

From the design ideas, we developed themes such as integrating audio as well as video introductions, customizing colours of the items, interacting with the items through drag and drop, have different levels and ability to select a certain level. They also liked colours of the items on display and in the shop scenario, they liked that it resembles a village boutique rather than a supermarket. However, some of the girls complained that in all artefacts, the player (avatar) is represented as a boy and we inferred that the ability to choose a male or female avatar is an important feature.

\subsection{Potential design of the application}

The design of the application will be informed by the findings from the workshops. We will also investigate the feasibility of gamification concepts as it is referred to the use of game design elements in non-game contexts[10]. Aligned with the concept of gamification, the application will be associating the following gamified features.

\section{Narrative}

Narrative refers to a story line which connects the activities together. It helps the activities to make sense. The two themes emerged (shopping and transportation) will be utilized in developing a story which the students can relate to. A child traveling by bus to a village boutique can be a potential story. The transactions he/she does along the way and at the boutique can be used as learning activities.

\section{Progression}

This refers to the importance of unlocking information continually. Accordingly, the application will consist of different stages and multiple levels in each stage. In order to progress through the stage, the users will have to complete the previous level. The difficulty will increase when they progress through the game. For instance, concepts such as saving, loan, performing transactions with cents will be introduced at the higher stages.

\section{Rewards and leaderboards}

As rewards for the system, a 5-point scoring/rewarding system will be developed with the use of stars. The better they perform the more stars they get. 


\section{Discussion and Lessons Learned}

In all our workshops, we did not work with an individual child, rather a group of children in the ages eight to nine. These children differ in knowledge, life experiences, and styles of exploring ideas. They need time to understand how to work as a team as well as learn to respect the ideas of others. Through these workshops, we understood that the adult participants need to be patient as the teams learn to be better at collaboration and work as a team of equals. From this section, we hope to build a discussion towards further exploring the findings and observations of the three prior workshops as well as present our ideas on what they speculate as design aspirations. The lessons we have learned by conducting co-design workshops in Sri Lanka and the challenges we faced as designers are further discussed.

\subsection{Design Inspirations}

It was clear that the children's everyday experiences and desires had a major impact on their drawing artefacts. As opposed to most major shopping themed mobile games, where the user (player) would visit a supermarket and choose items from the shelves, they preferred visiting kades (small village boutique) and ask for the items from the storekeeper. However, instead of items such as bags of rice and grains which can be commonly found in these type of kades, their drawings had a lot of sweets, toys, and fruits. It is arguable that this is a common observation of a child's drawing. However, the children expressed that they rarely get to buy items such as toys and fruits from the shops as they are expensive. The extreme poverty, some of these children undergo was another distinctive feature of these drawings. In addition to the items favoured to be bought, waiting for the cheaper government owned red colour buses, getting small amounts of money as a loan and the struggle to pay it back were seen as evidence of their hardships. Furthermore, the children wanted their designs to be as realistic as possible. Instances such as the arguments the children had on how the bus tickets are issued, the colours of the notes and the way values were written on the notes can be seen as examples of the effort the children have put into their design.

During the play room workshop, we observed that children face difficulties in understanding some of the common icons and interactions such as the next icon and swipes. Since the language used is foreign to these children, none of them understood what needs to be done. Highlighting what needs to be focused on have been used as a solution. However, some of the students were frustrated as they could not fully understand what needs to be done. This highlighted that first impression, as well as intuitive interactions, are important and signs and symbols we assume are globally understood not really be so. Therefore, we recommend that designers understand the experiences of these children and take design inspirations from these examples when designing and implementing technologies for rural Sri Lankan children.

We observed that the children produce a significantly higher number of design ideas than likes or dislikes. All the children started writing likes and dislikes but after some time they would start working on design ideas and kept working on it. The researchers had to ask the children specifically for likes and dislikes. While this is iden- 
tified as a common observation of sticky evaluation sessions, we believe that it is a reflection of the teacher-centered teaching and learning environment the children are immersed. From the observations, we noticed that the children treat the teacher as a knowledge hub and they expect her to give all answers. Even though there are attempts to get students involved in learning, it is common for Sri Lankan classrooms to be more bias towards a teacher-centric environment. Therefore, we believe that the children's reluctance to talk freely is the main reason for the lower numbers. However, we observed that several design ideas were correlated with dislikes. For instance, a dislike such as "I don't like the way the values of notes and coins are displayed", correlates to "The coins and notes should be represented by actual or realistic images of them instead of writing just the values". We also believe that it is a difficult task for children to provide likes and dislikes by exploring these types of low-fidelity paper prototypes. Therefore, we recommend that evaluation techniques to be used only after a functioning prototype is implemented, especially with children from the developing countries.

Lesson 01. Use a native language when designing and be mindful that some of the globally recognized icons and gestures are foreign to these children

\subsection{Unsuccessful Scaffolding}

We found that there was a lack of idea diversity in scenarios across all the groups. There were two common themes; shopping and transportation except for one exemplary case of debt collection. We believe that the activities of the play room workshop and the scaffolding nature are related to this lack of idea diversity. As mentioned above, during the playroom workshop, the children played few shopping-related games. Pedagogically, scaffolding refers to support given to students solve problems, while gradually removing those as students gain more knowledge [57]. We presume that while the play room workshop was successful in supporting children gradually learn the process of co-design, the scaffolding did not function properly when playing the mobile games. We speculate that instead of widening the boundaries of child's imagination it narrowed the scope, resulting in the generation of the similar type of ideas. However, the lack of ideas could also be due to the fact that these children have a limited exposure to finance and money transactions in their day-to-day life. The exception being, the child who witnessed the loan and repayment transaction

The limited time allocated for the play room workshop can be another reason for the lack of success in scaffolding. Even though we allocated one week for this, it could be seen that the children developed a wrong preconception about the design space during this week. It was evident that some of the children thought they are required to design something similar to what they have played. This can be due to the close relationship between the games they played and the design space they required to ideate. In the future when running similar kind of workshops and initiatives it might be good to meet with the children at least one month in advance. It is advisable to give children ample opportunity to interact with mobile games prior to the study as 
they have limited experience with these devices. We recommend that designers be cautious when selecting applications or games to be provided for the children. The selection has to be diverse in order for the children become familiar with game mechanics and features provided by the platforms. Playing different types of games will limit the preconception of design space among the children while allowing the children to get familiar with the devices of which they are designing games for. Additionally, it will provide an opportunity for the design teams to form a closer bond with each other (adults and children) as well as time for them to learn to work as a team.

Lesson 02. The children should be given opportunities to get familiar with the technologies of which they are designing to. However, researchers need to be mindful of the fact that this might lead to children developing a preconception about the design space.

Lesson 03. Sufficient time should be allocated for the ice breaking sessions as the children are not used to talk freely and express their ideas to an adult.

\subsection{Planning \& Management}

The role of adults within the team was critical. We as the adult participants had to be experts in the methods that were used and were responsible for planning the workshops. We guided the child designers in thinking about their experiences of interacting with money and ideated how to visualize those experiences in a form of a mobile application. Although we made sure not to ask "leading questions" we used "What if" questions to guide the students and engage them in thinking deep into their experiences. Since this study was done within a school, we had to stick to strict time intervals as we were allocated only one hour per session. However, it was an arduous task to keep to time as the children kept exploring their experiences and discussing them with adults and peers, which if we had been strict about time would have been a hindrance as well as some of the richness in ideas would have been lost. The fact that the children found this work more fun than the school work was the biggest concern when managing time.

Initially, we planned to conduct the Score workshop with standard sticky notes. However, during the play room workshop when the children were writing down likes and dislikes about the games they played, we discovered that they are struggling to write concise thoughts in a paper as small as sticky in the Sinhala language. These children have not yet started using pens and were writing using pencils. Hence, whenever they made a mistake, they would erase and write on the same paper. This made the sticky note dirty and the children did not want to work with them anymore. Instead, they asked for another sticky. Thus we decided to let them write on A4 size paper. Afterwards, the adult researchers got together and wrote down the ideas of children on sticky notes. Sometimes, the adult researchers had to interview the children to understand the meanings of what they have written as they were ambiguous. There was one instance where a child had mentioned "I like 1, 2, 3" and the child has 
meant to say that he liked the way the events are numbered so that he can understand the flow. Additionally, we identified that some cultural practices can also impact the student participation in this type of work. For example, in countries such as Sri Lanka, the students are trained to be passive learners. This makes it difficult for the children to participate in an activity such as "stickies" which require them to provide critical feedback. Therefore, we report that it is paramount that some initial time needs to be spent on getting the children familiar with the co-design approach before directly utilizing the methods used in the developed countries.

We also realized that there was a slight hostility from the other teachers of the school towards the study as they believed the children from one classroom is getting a preferential treatment. However, as native researchers, we understood this behaviour of other teachers since the school is one of the rural schools with limited infrastructure and resources. Hence some teachers believed that there are much more important basic amenities to be improved within the school before the introduction of technology. Thus we would suggest all future researchers follow proper channels of getting approvals before conducting longitudinal studies in Sri Lankan schools.

Lesson 04. Children face difficulties in writing concise thoughts on a small piece of paper (sticky note). Therefore, such evaluation methods cannot be used as it is.

\section{Conclusion}

The work explained above is part of a larger study focusing towards using tablet computers as a pedagogical tool towards improving financial literacy to overcome poverty. As it is identified that the financial education needed to be provided from a young age, our study explored the experiences of children in interacting with money and how they would visualize these experiences in a form of a story. Through a series of co-design workshops, we were able to gather design inspirations and useful concepts about how to design a mobile learning platform from a child's perspective. The children took part in the study as design partners and worked as equals with adult designers. Since these children are new to these type of activities, a scaffolder process is followed. While this was successful in getting children familiarized with the process of co-design, it was found to limit the children's boundary of imagination. Two themes became prominent when the drawing artefacts were analysed. Except for one case, all the designs fell into either the shopping theme or transportation. We realized that the children expect the applications to relate to their daily experiences and needed the visual elements to be as realistic as possible. The artefacts generated by the children were evaluated through stickies method where we were able to collect likes, dislikes and design ideas from the children's perspective which can be used to improve the artefacts of the children. Our future research will be directed towards implementing a fully functional prototype based on the findings of the study and evaluate it through a field study. It is our belief that even though our work is specifically focused on technology design for financial literacy with children, our findings and observation are valid for most design applications within the same context. 


\section{References}

1. R Abramovitch, J L. Freedman, and P Pliner. 1991. Children and money: getting an allowance, credit versus cash, and knowledge of pricing*. Journal of Economic Psychology 12, 1: 27-45.

2. S Ishtiaque A and S J Jackson. 2015. Residual Mobilities: Infrastructural Displacement and Post-Colonial Computing in Bangladesh. Proceedings of the 33rd ACM Conference on Human Factors in Computing Systems, 437-446.

3. Houman Alborzi, Allison Druin, Jaime Montemayor, et al. 2000. Designing StoryRooms: Interactive Storytelling Spaces for Children. Proceedings of the 3rd Conference on Designing Interactive Systems 2: 95-104.

4. Morgan G. Ames. 2015. Charismatic Technology. Proceedings of the 5th Decennial AARHUS Conference: 109-120.

5. L Benton, H Johnson, E Ashwin, M Brosnan, and B Grawemeyer. 2012. Developing IDEAS : Supporting Children with Autism within a Participatory Design Team. Proceedings of Conference on Human Factors in Computing Systems: 2599-2608.

6. Sondra G Beverly and Emily K Burkhalter. 2005. Improving the Financial Literacy and Practices of Youths. Children \& Schools 27, 2: 121-124.

7. Virginia Braun and Victoria Clarke. 2006. Using thematic analysis in psychology. Qualitative Research in Psychology 3, May 2015: 77-101.

8. Stewart Cohen and Jing-Jian Xiao. 1992. For Parents Particularly: Consumer Socialization-Children and Money. Childhood Education 69, 1.

9. DailyFT. 2015. Financial literacy for development. The DailyFT. Retrieved from http://www.ft.lk/article/500017/Financial-literacy-for-development

10. Sebastian Deterding, Dan Dixon, Rilla Khaled, and Lennart Nacke. 2011. From Game Design Elements to Gamefulness: Defining "Gamification." Proceedings of the 2011 annual conference extended abstracts on Human factors in computing systems - CHI EA '11, 2425.

11. Fenne van Doorn, Pieter Jan Stappers, and Mathieu Gielen. 2013. Design Research by Proxy: using Children as Researchers to gain Contextual Knowledge about User Experience. Proceedings of CHI 2013: 2883-2891.

12. Allison Druin. 1999. Cooperative inquiry: Developing new technologies for children with children. Proceedings of the SIGCHI conference on Human Factors in Computing Systems, January 1999: 592-599.

13. United States Department of the Treasury Office of Financial Education. 2002. Integrating financial education into school curricula: giving America's youth the educational foundation for making effective financial decisions throughout their lives by teaching financial concepts as part of math and reading curricula in elementary, mi. Washington, D.C.

14. Ron Eglash, Audrey Bennett, Casey O’Donnell, Sybillyn Jennings, and Margaret Cintorino. 2006. Culturally Situated Design Tools: Ethnocomputing from Field Site to Classroom. American Anthropologist 108, 2: 347-362.

15. Jerry Alan Fails, Mona Leigh Guha, and Allison Druin. 2013. Methods and Techniques for Involving Children in the Design of New Technology for Children. Foundations and Trends in Human-Computer Interaction 6, 2: 85-166.

16. A.G Fallis. 2013. Building the Sri Lankan Knowledge Economy. Journal of 
Chemical Information and Modeling 53, 9: 1689-1699.

17. Christopher Frauenberger and Judith Good. 2012. Interpreting input from children: a designerly approach. Proceedings of the SIGCHI Conference on Human Factors in Computing Systems - (CHI'12): 2377-2386.

18. Terri L. Friedline, William Elliott, and Ilsung Nam. 2011. Predicting savings from adolescence to young adulthood: A propensity score approach. Journal of the Society for Social Work and Research 2, 1: 1-22.

19. Farideh Hamidi, Farhad Ghorbandordinejad, Maryam Rezaee, and Mehdi Jafari. 2011. A comparison of the use of educational technology in the developed/developing countries. Procedia Computer Science, Elsevier, 374-377.

20. K P Hewagamage, H M S J Meewellewa, G K Munasinghe, and H A Wickramarachi. 2011. Role of OLPC to Empower ICT Adaptation in the Primary Education. Education in a technological world: communicating current and emerging research and technological efforts: 391-398.

21. J M. Hogarth. 2006. Financial education and economic development. International Conference on Improving Financial Literacy, Federal Reserve Board, 1-34.

22. L Irani, J Vertesi, P Dourish, K Philip, and R E Grinter. 2010. Postcolonial Computing: A Lens on Design and Development. Proceedings of CHI 2010 Conference on Human Factors in Computing Systems.

23. H Itenge-wheeler, E Kuure, M Brereton, and H Winschiers-. 2016. Co-creating an Enabling Reading Environment for and with Namibian Children. Proceedings of the 14th Participatory Design Conference, PDC '16, ACM, 131-140.

24. M Kam, M Akhil, AKumar, and J Canny. 2009. Designing Digital Games for Rural Children: A Study of Traditional Village Games in India. Proceedings of the SIGCHI Conference on Human Factors in Computing Systems , CHI 09, 3140.

25. A Kumar, A Tewari, G Shroff, D Chittamuru, M Kam, and J Canny. 2010. An exploratory study of unsupervised mobile learning in rural India. Proceedings of the 28th international conference on Human factors in computing systems CHI 10: 743-752.

26. S Kwon, S Oh, K Park, S Kim, and H So. 2015. Children as Participatory Designers of a New Type of Mobile Social Learning Application. Proceedings of the 17th International Conference on Human-Computer Interaction with Mobile Devices and Services Adjunct - MobileHCI '15: 862-869.

27. A Large, V Nesset, J Beheshti, and L Bowler. 2006. "Bonded design": A novel approach to intergenerational information technology design. Library \& Information Science Research 28, 1: 64-82. 4

28. M Larson, N Rajput, A Singh, and S Srivastava. 2013. I want to be Sachin Tendulkar!: a spoken english cricket game for rural students. Proceedings of the 2013 conference on Computer supported cooperative work: 1353-1364.

29. LBO. 2016. Education a priority, free tablets for students Lanka Business Online. Retrieved December 1, 2016 from http://www.lankabusinessonline.com/ education-a-priority-free-tablets-for-students-budget/

30. Thomas A Lucey and Duane M Giannangelo. 2006. Short Changed: The Importance of Facilitating Equitable Financial Education in Urban Society. Education and Urban Society 38, 3: 268-287. 
31. J Makhaeva, C Frauenberger, and K Spiel. 2016. Creating Creative Spaces for Co-Designing with Autistic Children - The Concept of a "Handlungsspielraum." Proceedings of the 14th Participatory Design Conference: PDC'16, 51-60.

32. Jennifer L. Metcalf and Cristina M. Atance. 2011. Do preschoolers save to benefit their future selves? Cognitive Development 26, 4: 371-382.

33. Ministry of Finance and Planning. 2013. Poverty Indicators. Sri Lanka. Retrieved from http://www.statistics.gov.lk/HIES/HIES2012_13FinalReport.pdf

34. Neema Moraveji, Jason Li, Jiarong Ding, Suze Woolf, Ann Arbor, and Microsoft Corporation. 2007. Comicboarding: Using Comics as Proxies for Participatory Design with Children. Proceedings of the SIGCHI Conference on Human Factors in Computing Systems - CHI '07, 1371-1374.

35. Michael J Muller. 1991. PICTIVE--An Exploration in Participatory Design. Proceedings of the SIGCHI Conference on Human Factors in Computing Systems Conference on Human Factors in Computing Systems, CHI '91,225-231.

36. Bonnie a Nardi. 1996. Studying context: A comparison of Activity Theory, Situated Action Models, and Distributed Cognition. Context and Conciousness: Activity Theory and Human Computer Interaction: 69-102.

37. Mariesa Nicholas, Penny Hagen, Kitty Rahilly, and Nathalie Swainston. 2012. Using participatory design methods to engage the uninterested. $P d c$ ' $12: 121$.

38. Nicurriculum. 2010. A guide to organising a money themed event for $4-11$ year olds. Northern Ireland. Retrieved from http://www.nicurriculum.org.uk/curriculum_microsite/financial_capability

39. A Otto, P Schots, J Westerman, and P Webley. 2006. Children's use of saving strategies:An experimental approach. Journal of Economic Psychology 27,1:57

40. Jan Pahl. 2008. Family finances, individualisation, spending patterns and access to credit. Journal of Socio-Economics 37, 2: 577-591.

41. Thanh Thi Hong Pham and Peter Renshaw. 2013. How to Enable Asian Teachers to Empower Students to Adopt Student-Centred Learning. Australian Journal of Teacher Education 38, 11: 65-85.

42. Jc. Read, D Fitton, and M Horton. 2013. Theatre, play doh and comic strips: Designing organic user interfaces with young adolescent and teenage participants. Interacting with Computers 25, 2: 183-198.

43. Jc Read, P Gregory, S MacFarlane, B McManus, P Gray, and R Patel. 2002. An investigation of participatory design with children-informant, balanced and facilitated design. Interaction Design and Children: 53-64.

44. Jc Read, Daniel Fitton, and Emanuela Mazzone. 2010. Using obstructed theatre with child designers to convey requirements. CHI'10 Extended Abstracts on $\mathrm{Hu}$ man Factors in Computing Systems: 4063-4068.

45. I Rodriguez, A Puig, V Cortada, and E Mar. 2015. Designing a Math Game for Children Using a Participatory Design Experience. The Eighth International Conference on Advances in Human-oriented and Personalized Mechanisms, Technologies, and Services, 28-35.

46. M Scaife, Y Rogers, F Aldrich, and M Davies. 1997. Designing for or designing with? Informant design for interactive learning environments. Human Factors in Computing Systems, 343-350.

47. G Sim, M Horton, and J C. Read. 2016. Sensitizing: Helping Children Design Serious Games for a Surrogate Population. Lecture Notes of the Institute for 
Computer Sciences, Social-Informatics and Telecommunications Engineering, LNICST 161: 58-65.

48. G Sim, J C Read, PGregory, and D Xu. 2015. From England to Uganda: Children Designing and Evaluating Serious Games. Human-Computer Interaction 30, 3 4: 263-293.

49. Lucy A Suchman. 2002. Practice-based design of information systems: Notes from the hyperdeveloped world. Information Society 18, 2: 139-144.

50. David Talbot. 2012. Given Tablets but No Teachers, Ethiopian Children Teach Themselves. MIT Technology Review, 7-9.

51. G Taxen, A Druin, C Fast, and M Kjellin. 2001. KidStory: a technology design partnership with children. Behaviour \& Information Technology 20, 2: 119-125.

52. Tali Te'eni-Harari. 2016. Financial Literacy among Children: The Role of Involvement in Saving Money. Young Consumers 17, 2.

53. G Tilakaratna. 2015. Social protectin and the MDGs in Sri Lanka. Implications for the post 2015 agenda.

54. Khai N. Truong, Gillian R. Hayes, and Gregory D. Abowd. 2006. Storyboarding: An Empirical Determination of Best Practices and Effective Guidelines. Proceedings of the 6th ACM conference on Designing Interactive systems -'06

55. UnitedNations. 2015. United Nations Millennium Development Goals. Retrieved June 24, 2016 from http://www.un.org/millenniumgoals/

56. Phillip J. VanFossen. 2003. Best Practice Economic Education for Young Children? It's Elementary! Social Education 67, 2: 90.

57. L. S. Vygotskiı̌, E Hanfmann, G Vakar, and A Kozulin. 2012. Thought and language. MIT Press.

58. G Walsh, Craig Donahue, and Emily E. Rhodes. 2015. KidCraft: Co-Designing within a Game Environment. Proceedings of the 33rd Annual ACM Conference Extended Abstracts on Human Factors in Computing Systems: 1205-1210.

59. Greg Walsh, Alison Druin, Mona Leigh Guha, et al. 2010. Layered elaboration: a new technique for co-design with children. Conference on Human Factors in Computing Systems, 1237-1240.

60. G Walsh, E Foss, J Yip, and A Druin. 2013. Octoract: An Eight-Dimensional Framework for Intergenerational Participatory Design Techniques. Proceedings of the SIGCHI Conference on Human Factors in Computing Systems -CHI, 2893.

61. M Warschauer, S Cotten, and M Ames. 2011. One Laptop per Child Birmingham: Case Study of a Radical Experiment. International Journal of Learning and Media 3, 2: 61-76.

62. WorldBank. 2016. World Bank Poverty Data. Retrieved from http://www.worldbank.org/en/topic/poverty/overview

63. Robert K. Yin. 2014. Analyzing Case Study Evidence: How to Start Your Analysis, Your Analytic Choices, and How They Work. In Case study research : design and methods (Fifth edit). SAGE Publications, Inc.

64. J Yip, A Druin, E Foss, et al. 2013. Children initiating and leading cooperative inquiry sessions. IDC 2013, 293-296.

65. J Yip, T Clegg, E Bonsignore, H Gelderblom, E Rhodes, and A Druin. 2013. Brownies or bags-of-stuff? Domain Expertise in Cooperative Inquiry with Children. Proceedings of the 12th International Conference on Interaction Design and Children - IDC '13: 201-210. 